\title{
Characterization of Water and Energy Consumptions at the End Use Level in Rural and Urban Environments: Preliminary Results of the ENERWAT Project
}

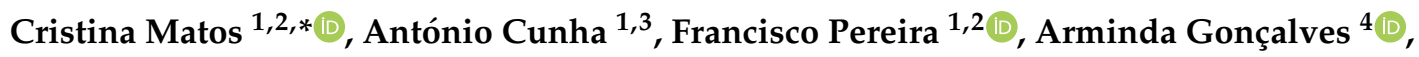 \\ Elisabete Silva ${ }^{1,2}$, Sandra Pereira ${ }^{1,2}\left(\mathbb{D}\right.$, Isabel Bentes ${ }^{1,2}\left(\mathbb{D}\right.$, Diana Faria ${ }^{1,2}$ and Ana Briga-Sá ${ }^{1,2}$ \\ 1 ECT-School of Science and Technology, University of Trás-os-Montes e Alto Douro UTAD, \\ Quinta de Prados, 5000-801 Vila Real, Portugal; acunha@utad.pt (A.C.); fsp@utad.pt (F.P.); \\ elisabeteccsilva@gmail.com (E.S.); spereira@utad.pt (S.P.); ibentes@utad.pt (I.B.); \\ dfaria@utad.pt (D.F.); anas@utad.pt (A.B.-S.) \\ 2 C-MADE-Centre of Materials and Building Technologies, University of Beira Interior, \\ 6201-001 Covilhã, Portugal \\ 3 INESC TEC-INESC Technology and Science (Formerly INESC Porto), 4200-465 Porto, Portugal \\ 4 CMAT-Centre of Mathematics, DMA-Department of Mathematics and Applications, University of Minho, \\ 4800-058 Guimarães, Portugal; mneves@math.uminho.pt \\ * Correspondence: crismato@utad.pt
}

Received: 29 November 2018; Accepted: 4 January 2019; Published: 9 January 2019

\begin{abstract}
The characterization of water and energy consumptions is essential in order to define strategies for their rational use. The way these resources are used in households is the path for efficient and rational management, interdependent from each other. It is believed that there are significant differences between the patterns of water and energy consumption in rural and urban areas, where influencing factors should also be identified. This article aims to provide some preliminary results of a research project named ENERWAT, with the main goal to characterize the relation between water and energy consumption at the end use level for urban and rural environments. One of the goals of the aforementioned project was the design, application, and results analysis of a survey, in order to find the main differences in the water and energy consumptions at the end use level and the factors that influence it in urban and rural households. A total of 245 households participated in the research during 2016 (110 urban dwellings and 135 rural), responding to questions on their family composition, dwellings characterization, water and energy consumption habits, and conservation behaviors of these resources. The project also includes the instrumentation and monitoring of dwellings in rural and urban environments to quantify the water consumption and related energy consumption. This stage is still in progress and includes in situ measurements of nine different households (four in rural and five in urban environments) during at least one year. In this article, some of the results obtained by the survey application and the in situ measurements are presented. Despite the large number of data and the associated complexity, it can be concluded that the joint analysis of the results allows identification of a connection between water and energy consumption, as well as a household's consumption patterns.
\end{abstract}

Keywords: energy to water nexus; ENERWAT project; survey; in situ measurements

\section{Introduction}

In a time where scarce resources and climate change are a concern, it is important to define water and energy efficiency strategies that minimize the damaging impact on the environment. It is, therefore, 
necessary to develop research work to quantify and characterize water and energy consumptions in order to define strategies for their rational use. Water and energy systems have been treated independently. However, water consumption directly affects energy consumption, and so those consumptions are closely related. The so-called "water-energy nexus" is where integrated study may lead to the identification of new solutions for saving these resources.

Human beings not only consume water directly, but also indirectly in food production, personal hygiene, sanitation, and many other industrial and domestic uses where energy consumption is also implicit. Since water is a strategic resource for a country's development, its efficient use must be ensured, providing not only its preservation, but also energy, financial, and environmental savings [1]. On the other hand, the growing demand for water, driven by population growth and increasing quality of life requirements, has also led to increased energy consumption. There is an interdependence between energy and water that becomes more complex as the energy crisis and impacts of climate change intensify, contributing to changes in water and energy consumption patterns [2].

The water-energy nexus has thus been recognized as a comprehensive concept to improve management practices in the water and energy sectors [3,4]. In this context, the interdependence of these two essential resources is receiving increasing attention, both from the scientific community and from the general community.

Knowledge of the most relevant factors influencing the domestic water and energy consumptions is a fundamental tool for efficient planning, operation, and maintenance of their distribution and availability [5]. Portugal is country that imports fossil fuels, which makes it dependent on energy resources [6].

Efficient use of energy is also key to building sustainability and is one of the priorities of European energy policy.

In 2013, the residential sector accounted for $16.7 \%$ of final energy consumption, where $27.2 \%$ corresponded to electricity consumption. In this context, this sector presents a great potential for energy efficiency measures implementation [7]. In Portugal, there are some emerging ideas about this subject. However, there is not enough information, and the distinction between consumption patterns in rural and urban environments is unknown. Regarding Portuguese regulations, there has been some concern about the interconnection between energy and water efficiency in buildings. The integration of efficiency of household appliances for water use in the achievement of buildings' energy performance through the National Energy Certification System (SCE) is already a reality. However, further work is still needed in this area.

In order to recommend strategies for water and energy conservation, it is necessary to characterize domestic consumption and also to collect information about the factors that may influence those consumptions, such as socio-demographic and housing characteristics, as well as household consumption patterns. Research work has already been developed in this domain by Matos [8,9]. It is expected to find significant differences between water and energy consumption patterns in urban and rural areas, but these differences have not yet been evaluated. This analysis is extremely important and has been referred to as essential for the future planning and delineation of strategic-political considerations. These differences are influenced by several factors that need to be identified.

It was with this concern in mind that the ENERWAT project was developed at the University of Trás-os-Montes and Alto Douro, dependent upon the participation of researchers from different areas. The project aimed to characterize energy consumption associated with domestic water consumption in rural and urban environments, while identifying factors influencing these consumptions. To achieve these goals, the project included user surveys and in situ measurements of dwellings located in both types of environments and the installation of an innovative on-site monitoring system.

It was also intended to create a simulator to help those building new housing to opt for solutions that lead to the consumption of less water and, consequently, less energy and, for those who already have a home, to choose new solutions that lead to the reduction of those same consumptions. At the same time, for each simulated case, a cost analysis was carried out to allow the user to make decisions. 
It also aimed to create a manual of good practices and improvement solutions that contributes to the reduction of water and energy consumptions. In this article, some preliminary results are presented, which were obtained during the development of the tasks related with the design and application of the survey and the instrumentation and monitoring for the acquisition of water and energy consumptions, in rural and urban environments.

\section{Methodology}

\subsection{Survey Application}

The survey was applied to 110 urban dwellings and 135 rural dwellings during 2016 in the district of Vila Real, located in Northern Portugal. Vila Real is a medium-sized city integrated in the area of the Douro Valley in the interior North region. A sample of households located in Vila Real County was selected.

This survey was prepared using an online tool called "onlinepesquisa.com", and it was applied door-to-door between December 2016 and January 2017.

Each household was surveyed in order to fill out the questionnaire on the spot, so that the researchers could explain relevant issues in person to ensure that the data was correctly collected. The fact that it was applied door-to-door allowed a high number of valid answers given the fact that the questions were immediately clarified. Only one person per family unit (regardless of gender) answered the survey questions, and participation was voluntary.

This survey allowed collection of different information, which is grouped and summarized in Table 1. It integrated 74 questions grouped into 6 categories. All of these questions were based on the state-of-the-art [10-18].

Table 1. Categories of the issues addressed in the survey.

\begin{tabular}{|c|c|}
\hline Categories & Collected Information \\
\hline 1. Characterization of the household & Number of members; age; qualifications; professional activity; family income. \\
\hline 2. Dwelling characterization & Environment location (rural or urban); area and typology of housing. \\
\hline 3. Energy consumption & Energy source used; electrical equipment; total energy consumption. \\
\hline 4. Water consumption & $\begin{array}{l}\text { Type of water supply, number, and duration of baths/showers, total water } \\
\text { consumption. }\end{array}$ \\
\hline 5. Clothes washing & $\begin{array}{l}\text { Washing machine; class of machine efficiency; number and duration of uses; } \\
\text { hand wash. }\end{array}$ \\
\hline 6. Dish washing & $\begin{array}{l}\text { Dishwasher; class of machine efficiency; number and duration of dishwasher } \\
\text { use; hand wash. }\end{array}$ \\
\hline
\end{tabular}

Regarding water and energy consumption, since most households were unable to provide the exact data of the monthly bill in relation to the year 2016, the question was thus what was the range of values that were paid per month of water, electricity, and natural gas consumptions? For other sources of energy used (firewood, pellets, briquettes, diesel, bottled LPG, etc.) the annual costs were requested. After collecting the answers on all household consumption, monthly costs $(€)$ (in the case of water, electricity, and natural gas) were converted into monthly consumption $\left(\mathrm{m}^{3}, \mathrm{kWh}\right)$, based on the EMARVR collection form and EDP Vila Real (local entities responsible for the distribution of water and energy-electricity and natural gas-, respectively). In the particular case of electric power, the normal and double tariff consumption was calculated separately.

The mode of monthly average consumption (for the surveyed year) was calculated for rural and urban environments (Figures 1-4). For the remaining energy sources, the monthly average of consumption value (toe-tons of oil equivalent) was calculated using the amount spent $(€)$ and quantity $(\mathrm{kg}, \mathrm{L})$ using the conversion factors available for the various types of energy.

Several variables (quantitative and qualitative) were collected in order to try and obtain the differentiating factors between rural and urban environments. 


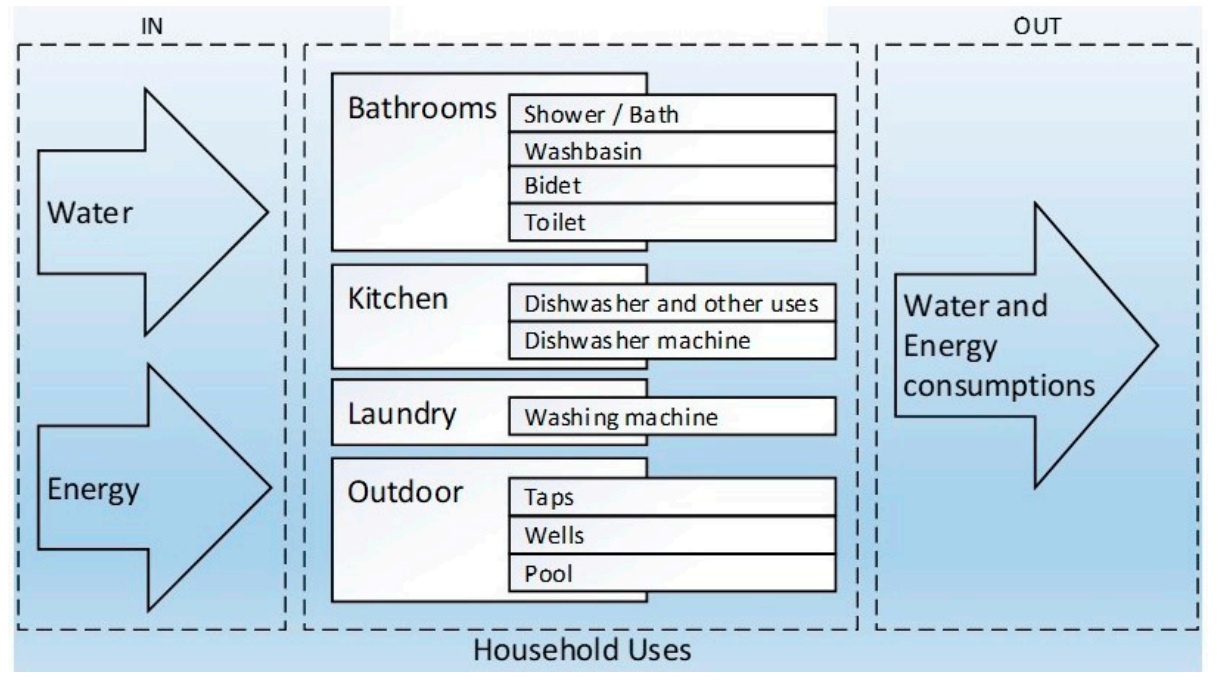

Figure 1. WATERS model defined in the ENERWAT project to characterize in situ measurements of water and energy consumptions (adapted from [10]).

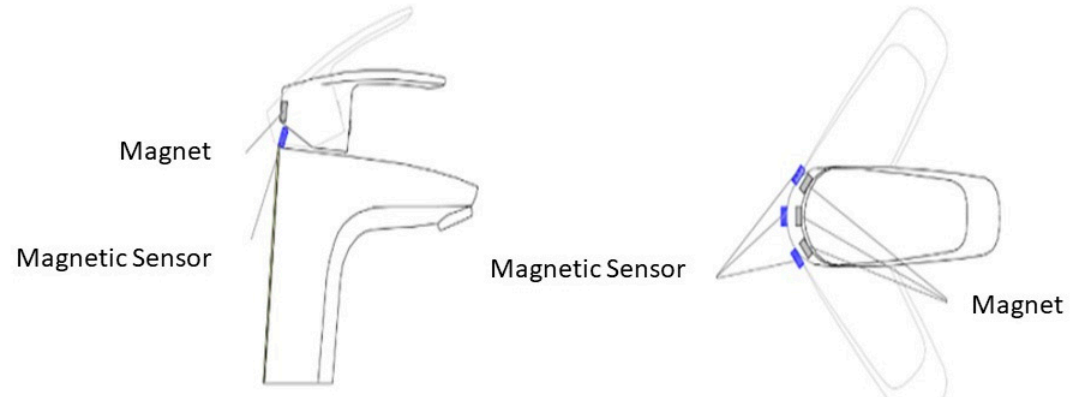

Figure 2. Placement of sensors on taps (adapted from [10]).

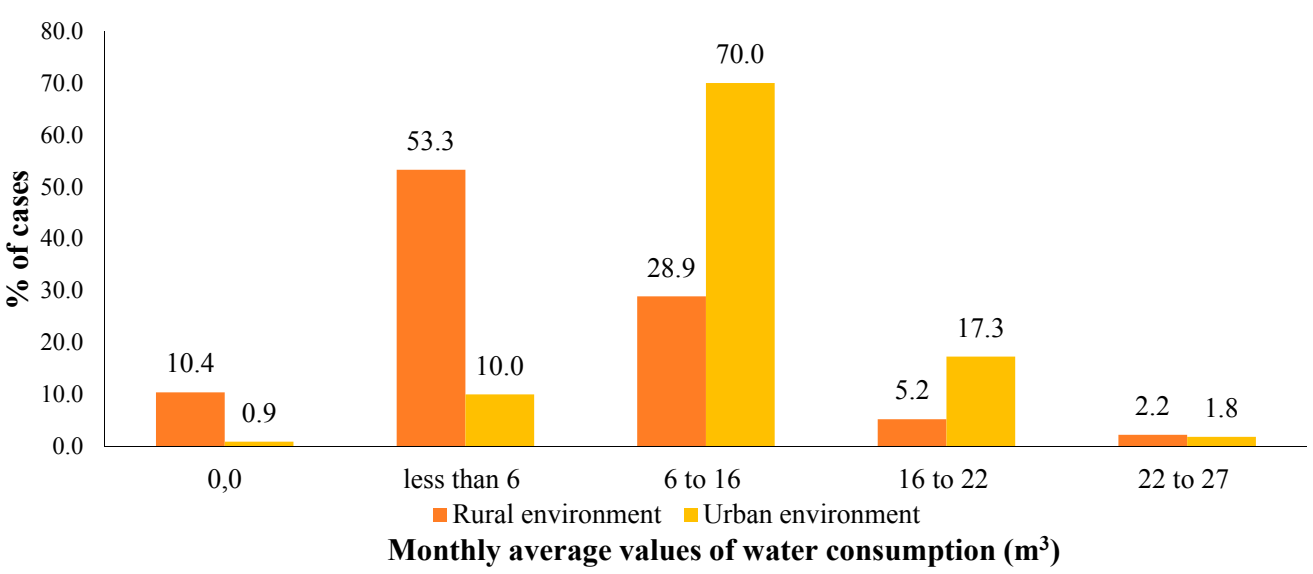

Figure 3. Monthly average of water household consumption in rural and urban areas for the surveyed year (adapted from [19]).

Statistical analyses were performed to analyze and present the data. IBM SPSS Statistics 23.0 was used for data analysis. Special highlighting was given to the exploratory data analysis. Descriptive statistics (absolute and relative frequency, mean, mode, range, and standard deviation) of the variables through rural and urban areas were used to summarize the survey results and to characterize water and energy consumption. Non-parametric hypothesis tests were applied in order to compare and distinguish the variables collected in rural versus urban environments. The results from these statistical analyses were already published by the authors in Reference [19]. 


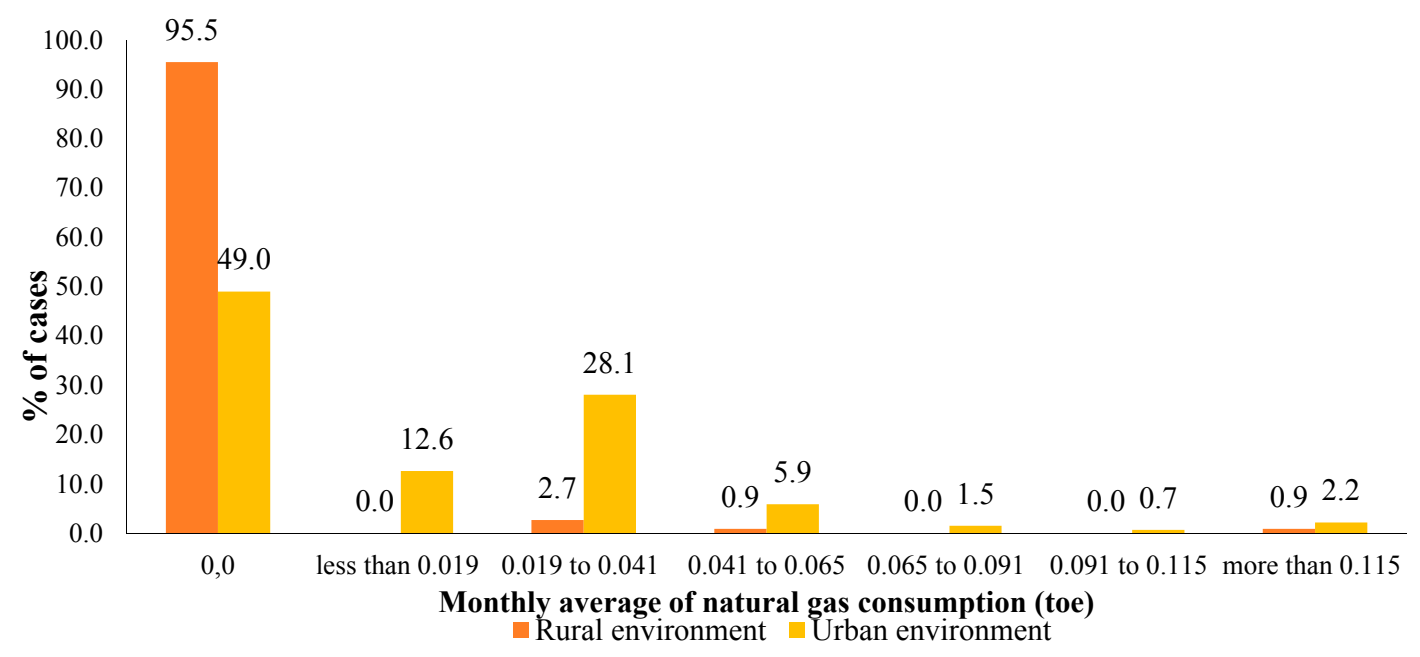

Figure 4. Monthly average of natural gas consumption in rural and urban areas (adapted from [19]).

\subsection{Instrumentation and Monitoring}

It is intended with the instrumentation and monitoring of dwellings in rural and urban environments to quantify the water consumption and the related energy consumption. In addition to the measurements, the characterization of housing and household behavior patterns were also carried out. This stage is still in progress and includes in situ measurements of 9 different households (4 in rural and 5 in urban environments) during at least one year. Presentation of the results of water and energy consumptions acquired during one week (between 27 March and 2 April, 2017) were an example of the data that can be obtained through the instrumentation and monitoring of the different devices in a household. The presented data refers to a monitored dwelling located in an urban area of the city of Vila Real, occupied by a standard Portuguese family, where a couple lived with a teenager son. It was composed of three bedrooms, two bathrooms, and a kitchen. A dishwashing machine and a laundry machine were used. The dwelling was supplied by public water, electricity, and natural gas. The water heating was ensured by natural gas. Users already had some efficiency patterns concerning the water and energy consumptions, verified through the use of a flow reducer in the shower device and the absence of hot water in the bidet and washbasin.

A continuous measurement of water and energy consumptions was carried out in this dwelling following the model named WATERS defined in the ENERWAT project, Figure $1[10,20]$.

Water consumption monitoring was carried out on all existing water use devices (washbasin, shower, bidet, toilet, dishwasher, washing machine, and dishwasher) and also on the water meter. Energy consumption was quantified by monitoring the counters of their respective energy sources, in this case, electricity and gas.

The experimental setup was composed by central nodes, sensors and cables, and a central server. The nodes were small board computers (SBC) placed at strategic sectors of the dwelling in order to acquire the states of the taps, machines, water heaters, and meters. A virtual private network (VPN) was used for daily upload of acquired data to the central server, where it was stored in a database. On/off sensors were placed in the water usage devices. Magnets and magnetic sensors were placed on the faucets and water flushing systems of the flushing cisterns, and voltage sensing sensors were used between the washing machines and the respective sockets feed [9]. The placement of magnetic sensors on the taps made it possible to check the opening (ON) and the lock (OFF) and whether they were charging hot water, cold water, or hot/cold water (Figure 2). Image consumption readings were performed on water, gas, and electricity meters using webcams. It was possible to capture images of the values recorded in the counters whenever there was a change in the digits, which corresponded to a change in consumption. Subsequently, it was necessary to compare the results obtained by triggering the sensors with those obtained by changing the digits shown in the meter display. This comparison 
made it possible to identify the water consumption devices used, the consumption of water (hot or cold), the period of use, and the source of energy used (electricity or gas) and their consumption. Cables were used to guarantee the connection between sensors and nodes.

\section{Results and Discussion}

\subsection{Survey Application}

A brief analysis of the results made possible the conclusion that the annual water consumption was higher in the urban environment, with values between 6 and $16 \mathrm{~m}^{3}$, corresponding to $70 \%$ of the analyzed cases (Figure 3). In the natural gas consumption, it was observed, as expected, that its use had no significance in the rural environments, given that these areas were not served by the respectively municipal infrastructures (Figure 4). With regard to the annual average of electric energy consumptions, it was highlighted that the predominance of use was simple tariffs when compared with the double tariff (Figures 5 and 6).

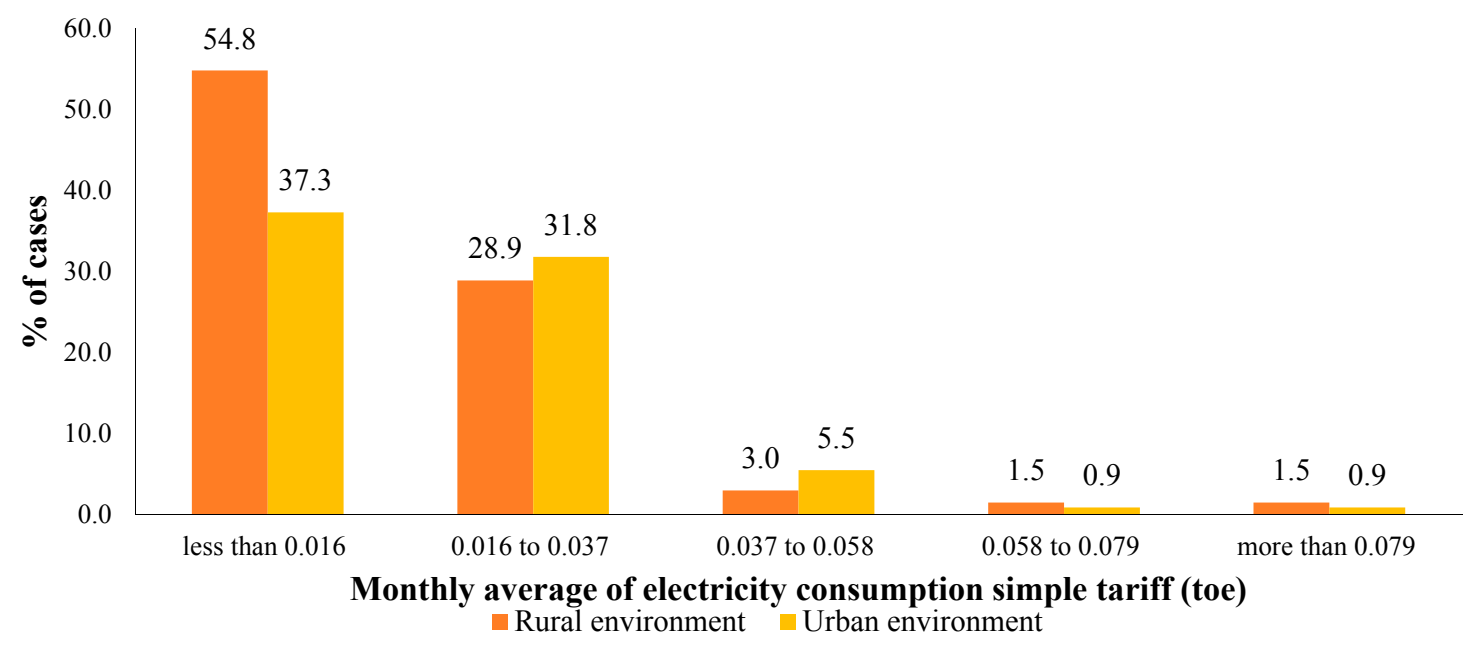

Figure 5. Monthly average of electric energy (simple tariff) consumption in rural and urban areas (adapted from [19]).

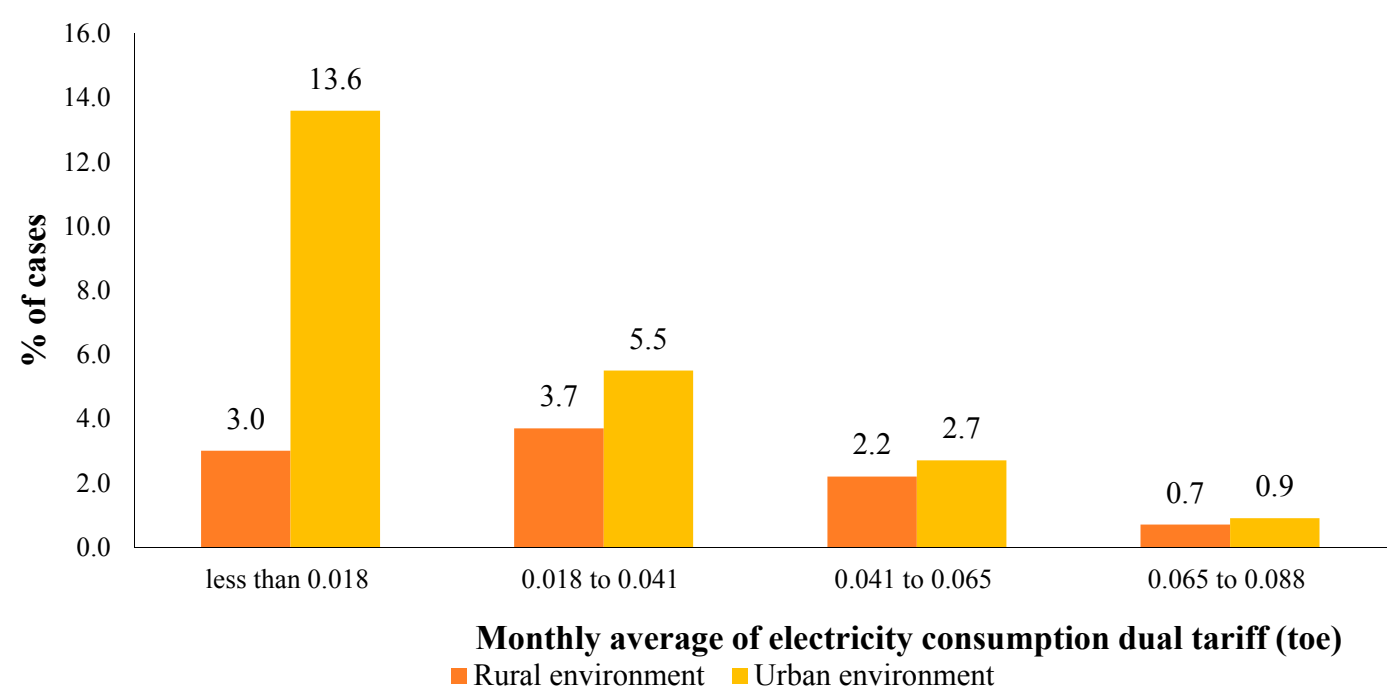

Figure 6. Monthly average of electric energy (double tariff) consumption in rural and urban areas (adapted from [19]). 
From the application of non-parametric hypothesis tests, it was revealed that these variables/factors were statistically significant in the distinction of the behavior of their distributions in the rural and urban environments analyzed [18]. In the referenced paper, several differences between rural and urban environments were found. The research started by considering 80 variables based on the bibliography, which decreased to 42 after the statistical treatment of the survey data [19]. Only 42 variables remained as truly distinguishing factors of rural and urban environments, and thus as possible determinants of water and energy consumptions.

All the 42 differentiating variables that resulted from this study may be able to justify these differences.

\subsection{In Situ Measurements}

Figure 7 shows an example of the type of results that can be obtained through the instrumentation and monitoring of the household consumptions. The accumulated and the hourly average values of water and energy consumption (electricity and gas) obtained for a day of the week for the studied dwelling are presented. It is possible to observe the periods when there was water consumption and what type of energy source was linked to that use. An hourly analysis showed the variation of energy and water use during the day and if it included a large period, such as a week, a month, or a year can lead to identify behavior patterns. As previously stated, in situ measurements of different households are still in progress and consumption values will be obtained for at least one year. These values will be important to identify the influencing factors of water and energy consumptions, namely the seasonality.

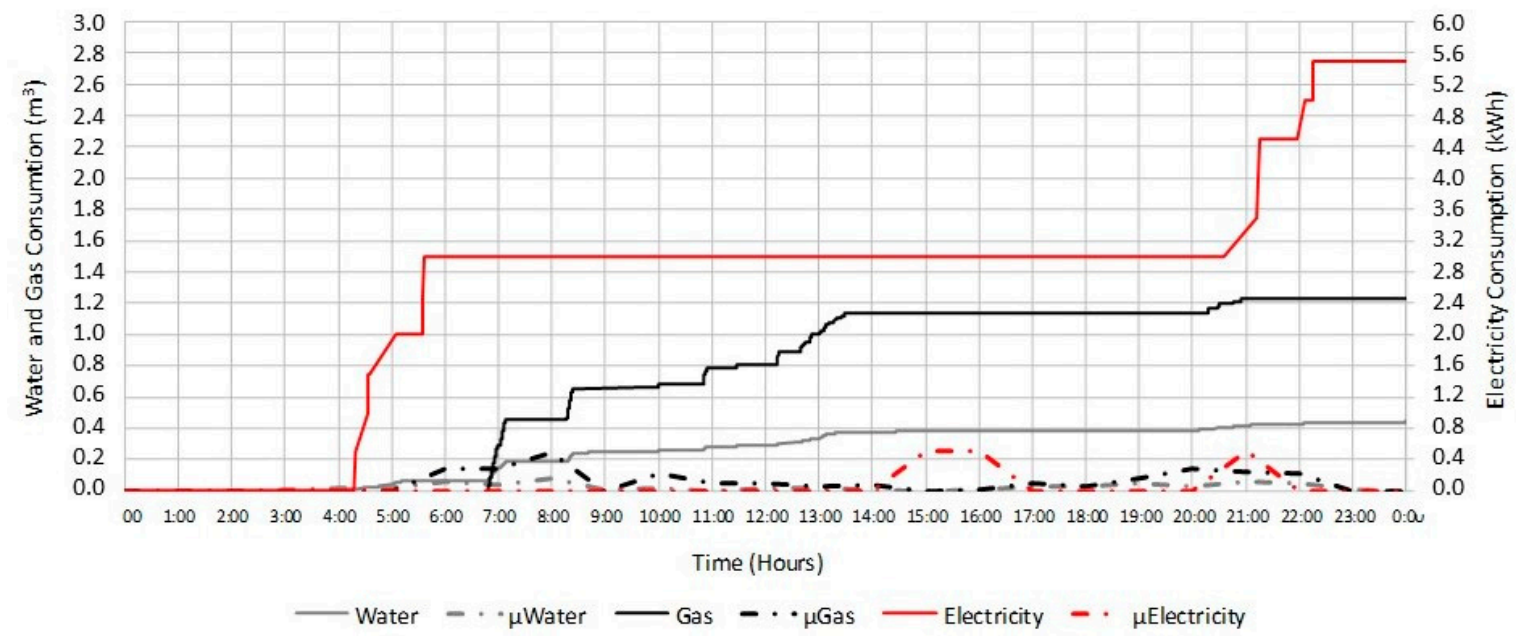

Figure 7. Accumulated and average hourly $(\mu)$ values of water, electricity, and gas consumptions.

Given the continuous measurement of the consumptions, the simultaneous use of the different devices was identified. This was essential to determine the consumption per event and per device. Table 2 presents the identification of the simultaneous events for the measured week. It was observed that the higher number of simultaneous events occurs between the shower/bath and the toilet flush, corresponding to 15 events. It was also observed that shower/bath is the most used equipment in this house $(42 \%)$ for this week. Toilet flush consumptions were analyzed and the isolated events were identified. This type of analysis allowed determination of the isolated consumptions for other events where the devices were simultaneously activated. The average consumption per device for the measured week was achieved (Table 3). The average duration of each device use was also determined. In addition to the high values found for dishwasher and washing machines, it was observed that an average value of $9.69 \mathrm{~min}$ was obtained for the shower/bath, presenting higher values of hot water consumption and, consequently, natural gas. 
Table 2. Identification of the simultaneous events.

\begin{tabular}{cccccccc}
\hline USES & SHOWER/BATH & $\begin{array}{c}\text { TOILET } \\
\text { FLUSH }\end{array}$ & WASHBASIN & DISHWASHER & $\begin{array}{c}\text { WASHING } \\
\text { MACHINE }\end{array}$ & $\begin{array}{c}\text { KITCHEN } \\
\text { SINK }\end{array}$ & TOTAL \\
\hline SHOWER/BATH & - & 15 & 0 & 4 & 1 & 2 & 22 \\
TOILET FLUSH & 15 & - & 7 & 4 & 5 & 3 & 19 \\
WASHBASIN & 0 & 7 & - & 1 & 5 & 0 & 6 \\
DISHWASHER & 4 & 4 & 1 & - & 1 & 2 & 3 \\
WASHING & 1 & 5 & 5 & 1 & - & 2 & 2 \\
MACHINE & 2 & 3 & 0 & 2 & 2 & - & 0 \\
KITCHEN SINK & 22 & 19 & 6 & 3 & 2 & 0 & 52 \\
TOTAL & & & & & & & \\
\hline
\end{tabular}

Table 3. Average consumption of water, gas, and electricity per device and per event.

\begin{tabular}{|c|c|c|c|c|c|}
\hline \multirow{3}{*}{ DEVICES } & \multirow{3}{*}{$\begin{array}{c}\text { AVERAGE } \\
\text { DURATION/EVENT } \\
\text { (MINUTES) }\end{array}$} & \multicolumn{4}{|c|}{ AVERAGE CONSUMPTION/EVENT } \\
\hline & & \multicolumn{2}{|c|}{ WATER } & \multirow{2}{*}{$\frac{\text { GAS }}{\text { HOT WATER }(\mathrm{kWh})}$} & \multirow{2}{*}{$\begin{array}{c}\text { ELECTRICITY } \\
\text { MACHINES (kWh) }\end{array}$} \\
\hline & & HOT (L) & COLD (L) & & \\
\hline BATHS & 9.69 & 65.60 & 0.00 & 3.09 & 0.00 \\
\hline TOILET FLUSH & 0.70 & 0.00 & 5.29 & 0.00 & 0.00 \\
\hline $\begin{array}{l}\text { HANDWASH } \\
\text { BASIN }\end{array}$ & 0.16 & 0.00 & 1.75 & 0.00 & 0.00 \\
\hline DISHWASHER & 68.30 & 38.10 & 0.00 & 0.00 & 2.08 \\
\hline $\begin{array}{l}\text { WASHING } \\
\text { MACHINE }\end{array}$ & 57.73 & 54.15 & 0.00 & 0.00 & 1.14 \\
\hline KITCHEN SINK & 0.89 & 6.13 & 3.82 & 0.33 & 0.00 \\
\hline
\end{tabular}

A daily analysis of the water and energy consumptions for the week was also done. Table 4 presents the total water consumption, describing the one that was related to hot water and machines use. Energy consumption was separated into use of natural gas (used for showers/baths) and use of electricity (used for the dishwasher and washing machines). The conversion of energy consumption to primary energy (toe) and the calculation of the respective $\mathrm{CO}_{2}$ emissions allowed analysis on the impact of those consumptions on the environment.

Table 4. Daily consumptions of water, gas and electricity.

\begin{tabular}{|c|c|c|c|c|c|c|c|c|c|}
\hline \multirow{3}{*}{ DATE } & \multicolumn{3}{|c|}{ WATER } & \multicolumn{6}{|c|}{ ENERGY } \\
\hline & \multirow{2}{*}{$\begin{array}{l}T \\
\end{array}$} & \multirow{2}{*}{$\begin{array}{c}\text { HW } \\
L\end{array}$} & \multirow{2}{*}{$\begin{array}{c}\text { MW } \\
\text { L }\end{array}$} & \multicolumn{3}{|c|}{ GAS-HW } & \multicolumn{3}{|c|}{ ELECTRICITY-M } \\
\hline & & & & kWh & $\mathrm{kg} \mathrm{CO} / 2 / \mathrm{kWh}$ & Toe & kWh & $\mathrm{kg} \mathrm{CO} / 2 / \mathrm{kWh}$ & Toe \\
\hline 27 March 2017 & 629.00 & 340.15 & 131.98 & 19.95 & 6.52 & 0.001716 & 2.00 & 0.65 & 0.000172 \\
\hline 28 March 2017 & 465.00 & 356.91 & 76.30 & 15.95 & 5.21 & 0.001371 & 3.50 & 1.14 & 0.000301 \\
\hline 29 March 2017 & 550.50 & 220.78 & 197.95 & 10.14 & 3.32 & 0.000872 & 5.00 & 1.64 & 0.000430 \\
\hline 30 March 2017 & 495.00 & 403.52 & 55.00 & 17.92 & 5.86 & 0.001541 & 1.50 & 0.49 & 0.000129 \\
\hline 31 March 2017 & 444.00 & 368.10 & 75.90 & 14.21 & 4.65 & 0.001222 & 5.50 & 1.80 & 0.000473 \\
\hline 1 April 2017 & 438.00 & 326.42 & 20.00 & 14.92 & 4.88 & 0.001283 & 2.00 & 0.65 & 0.000172 \\
\hline 2 April 2017 & 441.50 & 324.80 & 50.51 & 14.57 & 4.76 & 0.001253 & 1.00 & 0.33 & 0.000086 \\
\hline Total & 3463.00 & 2340.68 & 607.65 & 107.65 & 35.20 & 0.009258 & 20.50 & 6.70 & 0.001763 \\
\hline Average & 494.71 & 334.38 & 86.81 & 15.38 & 5.03 & 0.001323 & 2.93 & 0.96 & 0.000252 \\
\hline $\begin{array}{l}\text { Standard } \\
\text { Deviation }\end{array}$ & 71.47 & 57.03 & 59.74 & 3.09 & 1.01 & 0.000266 & 1.77 & 0.58 & 0.000152 \\
\hline
\end{tabular}

T: Total consumption per day; HW: Hot water consumption per day; MW: Machines water consumption; GAS-HW: Gas consumption associated with the consumption of hot water; ELECTRICITY-M: Electricity consumption associated with washing machine and dishwasher.

\section{Conclusions}

The preliminary results revealed by the surveys indicated differences between domestic consumption of water, electricity, and natural gas, between rural and urban areas. There appeared to be some seasonality in the collected data. It revealed significant differences between the sociodemographic variables in the rural and urban environments. So, it was important to identify the predominant variables in the differences found in the water and energy consumption, which analysis is in progress 
at the moment. In the future, it would be interesting to extend the application of the survey to other regions of the country in order to identify the main differences between the different regions.

The work developed so far allowed the continuous collection of data in situ through a simple monitoring system. The instrumentation and monitoring of the different dwellings allowed obtaining of water and energy consumptions, identifying the water consumption for the different devices (hot or cold), the periods of use, and the energy source (electricity or gas) related with water use and their consumption values. The acquired data was important to define a correlation between energy and water consumptions for different devices and showed that a continuous measurement would allow identification of consumptions patterns and user behaviors.

The results obtained through the survey application and the in situ measurement were an added value to the characterization of water and energy consumptions at the end use level and were extremely important to identify the influencing factors of the consumption values and define future strategies of water and energy efficiency.

Author Contributions: Conceptualization, C.M. and A.B.; Methodology, C.M. and A.B.; Investigation, C.M., A.C., F.P., A.G., E.S., S.P., I.B., D.F. and A.B.; Resources, C.M., A.C., F.P., A.G., E.S., S.P., I.B., D.F. and A.B.; Data Curation, C.M., A.C., F.P., A.G., E.S., S.P., I.B., D.F. and A.B.; Writing-Review \& Editing, C.M. and A.B.; Project Administration, S.P.

Acknowledgments: This work was partially funded by project POCI-0-0145-FEDER-016730 (PTDC/AAG-REC/4700/2014) under the name ENERWAT: Water for energy: characterization, modelling and measures for reducing domestic urban and rural consumption, funded by the Foundation for Science and Technology and co-financed by the European Regional Development Fund (ERDF) through COMPETE 2020-Operational Competitiveness and Internationalization Program (POCI). This work was partially supported by the FCT (Portuguese Foundation for Science and Technology) through the project PEst-OE/ECI/UI4082/2013 (C-MADE). The research of the A. Manuela Gonçalves author was partially financed by Portuguese Funds through FCT (Fundação para a Ciência e a Tecnologia) within the Project UID/MAT/00013/2013.

Conflicts of Interest: The authors declare no conflict of interest.

\section{References}

1. Gleick, P.H. Basic Water Requirements for Human Activities: Meeting Basic Needs; Pacific Institute for Studies in Development, Environment and Security: Oakland, CA, USA, 1996.

2. Gregório, V;; Martins, M.Q. Conexões para uma nova sustentabilidade. In Proceedings of the Congresso de Geografia Portuguesa, Lisbon, Portugal, 26-29 October 2011; pp. 1-6. (In Portuguese)

3. Vieira, A.S.; Ghisi, E. Water-energy nexus in houses in Brazil: Comparing rainwater and gray water use with a centralized system. Water Sci. Technol. Water Supply 2016, 16, 274-283. [CrossRef]

4. Hoover, J.H.; Scott, C.A. The Arizona Water-Energy Nexus: Electricity for Water and Wastewater Services. In Proceedings of the 2009 Association of American Geographers Annual Meeting, Las Vegas, NV, USA, 22-27 March 2009.

5. Loureiro, D.; Pinheiro, L.; Rebelo, M.; Salgueiro, A.R.; Medeiros, N.; Covas, D.; Alegre, H. Estudo dos fatores mais relevantes que influenciam o consumo doméstico de água: $\mathrm{O}$ caso de estudo do complexo de edifícios: Twin-Towers. In Proceedings of the LNEC, Covilhã, Portugal, 14-17 October 2008.

6. EEA. 2015. Available online: https://www.eea.europa.eu/soer/countries/pt/national-and-regional-storyportugal (accessed on 10 September 2018).

7. Ferreira, J. O Consumo de Eletricidade do Setor Residencial em Portugal: Fatores Explicativos. Master's Thesis, Faculdade de Engenharia da Universidade do Porto, Porto, Portugal, 2015.

8. Matos, C.; Pereira, S.; Amorim, E.V.; Bentes, I.; Briga-Sá, A. Wastewater and Greywater reuse on irrigation in centralized and decentralized systems-An integrated approach on water quality, energy consumption and $\mathrm{CO}_{2}$ emissions. Sci. Total Environ. 2014, 493, 463-471. [CrossRef] [PubMed]

9. Matos, C.; Briga-Sá, A.; Bentes, I.; Faria, D.; Pereira, S. In situ evaluation of water and energy consumptions at the end use level: The influence of flow reducers and temperature in baths. Sci. Total Environ. 2017, 586, 536-541. [CrossRef] [PubMed]

10. Cunha, A.; Silva, E.; Pereira, F.; Briga-Sá, A.; Pereira, S. From water to energy: Low cost water \& energy consumptions readings. Procedia Comput. Sci. 2017, 121, 960-967. [CrossRef] 
11. Binks, A.N.; Kenway, S.J.; Lant, P.A.; Head, B.W. Understanding Australian household water-related energy use and identifying physical and human characteristics of major end uses. J. Clean. Prod. 2016, 135, 892-906. [CrossRef]

12. Basu, M.; Hoshino, S.; Hashimoto, S.; DasGupta, R. Determinants of water consumption: A cross-sectional household study in drought-prone rural India. Int. J. Disaster Risk Reduct. 2017, 24, 373-382. [CrossRef]

13. Haziq, M.A.; Panezai, S. Na empirical analysis of domestic water sources, consumption and associated factors in Kandahar City, Afghanistan. Resour. Environ. 2017, 7, 49-61. [CrossRef]

14. Keshavarzi, A.R.; Sharifzadeh, M.; Kamgar Haghighi, A.A.; Amin, S.; Keshtkar, S.; Bamdad, A. Rural domesticwater consumption behaviour: A case study in Ramjerd area, Fars province, I.R. Iran. Water Res. 2006, 40, 1173-1178. [CrossRef] [PubMed]

15. Singh, O.; Turkiya, S. A survey of household domestic water consumption patterns in rural semi-arid village, India. GeoJournal 2013, 78, 777-790. [CrossRef]

16. Hu, S.; Yan, D.; Guo, S.; Cui, Y.; Dong, B. A survey on energy consumption and energy usage behaviour of households and residential building in urban China. Energy Build. 2017, 148, 366-378. [CrossRef]

17. Martinez-Santos, P. Determinants for water consumption from improved sources in rural villages of southern Mali. Appl. Geogr. 2017, 85, 113-125. [CrossRef]

18. Fan, L.; Gai, L.; Tong, Y.; Li, R. Urban water consumption and its influencing factors in China: Evidence from 286 cities. J. Clean. Prod. 2017, 166, 124-133. [CrossRef]

19. Matos, C.; Bentes, I.; Pereira, S.; Gonçalves, A.M.; Faria, D.; Briga-Sá, A. Which are the factors that may explain the differences in water and energy consumptions in urban and rural environments? Sci. Total Environ. 2018, 642, 421-435. [CrossRef] [PubMed]

20. Briga-Sá, A.; Faria, D.; Silva, E.; Pereira, S.; Cunha, A.; Matos, C. Experimental analysis on energy and water consumptions at the domestic end use level: The particular case of showers. In Proceedings of the CIB W062, Ponta Delgada-Azores, Portugal, 28-30 August 2018.

(C) 2019 by the authors. Licensee MDPI, Basel, Switzerland. This article is an open access article distributed under the terms and conditions of the Creative Commons Attribution (CC BY) license (http:/ / creativecommons.org/licenses/by/4.0/). 